\section{Underground networking}

Above ground, plants compete for life-giving sunlight, but below the surface a more complex picture emerges. John Whitfield explores the role of mycorrhizae in plant ecology.

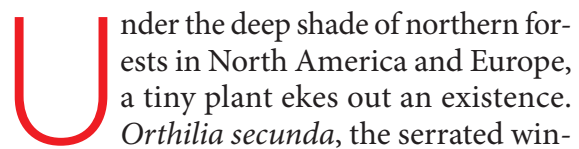
tergreen, is found huddled in the understorey of pines and birches, sending up a drab bundle of yellow-green flowers. Beneath ground, however, this meek plant hides a secret. Starved of sunlight, Orthilia has found another source of nourishment. Its roots tap into a network of soil fungi, taking up to half the carbohydrates it needs from organisms that normally form mutually beneficial relations with plants but giving nothing back.

"You could say that the plant is eating the fungus," says Marc-André Selosse of the Centre of Functional Ecology and Evolution in Montpelier, France, one of the team that detected Orthilia's thieving ${ }^{1}$. But Orthilia is also, indirectly, eating other plants - probably the very trees that tower over it. After all, it is their photosynthetic efforts that the fungus is feeding on. Indeed, Orthilia's freeloading may reveal the actions of an invisible hand in ecology; that is, the fungal network that underlies the forest and participates in a cooperative give-and-take with hundreds of plants.

Emerging clues suggest that this covert subterranean interplay influences many aspects of the forest community, including which plants live, which die, the effects of physical stresses such as heat and drought, and what happens after the introduction of new species. Add the controversial possibility that fungi mediate resource sharing between different plant species and a picture emerges of a Robin Hood of the soil, subsidizing those less able to make food, and by so doing, helping its own cause by promoting a diverse range of plant partners.

Just how interactive this fungal support system is remains unclear. The key processes happening underground are carried out by microscopic players and are hard to track. Moreover, no one knows how to measure

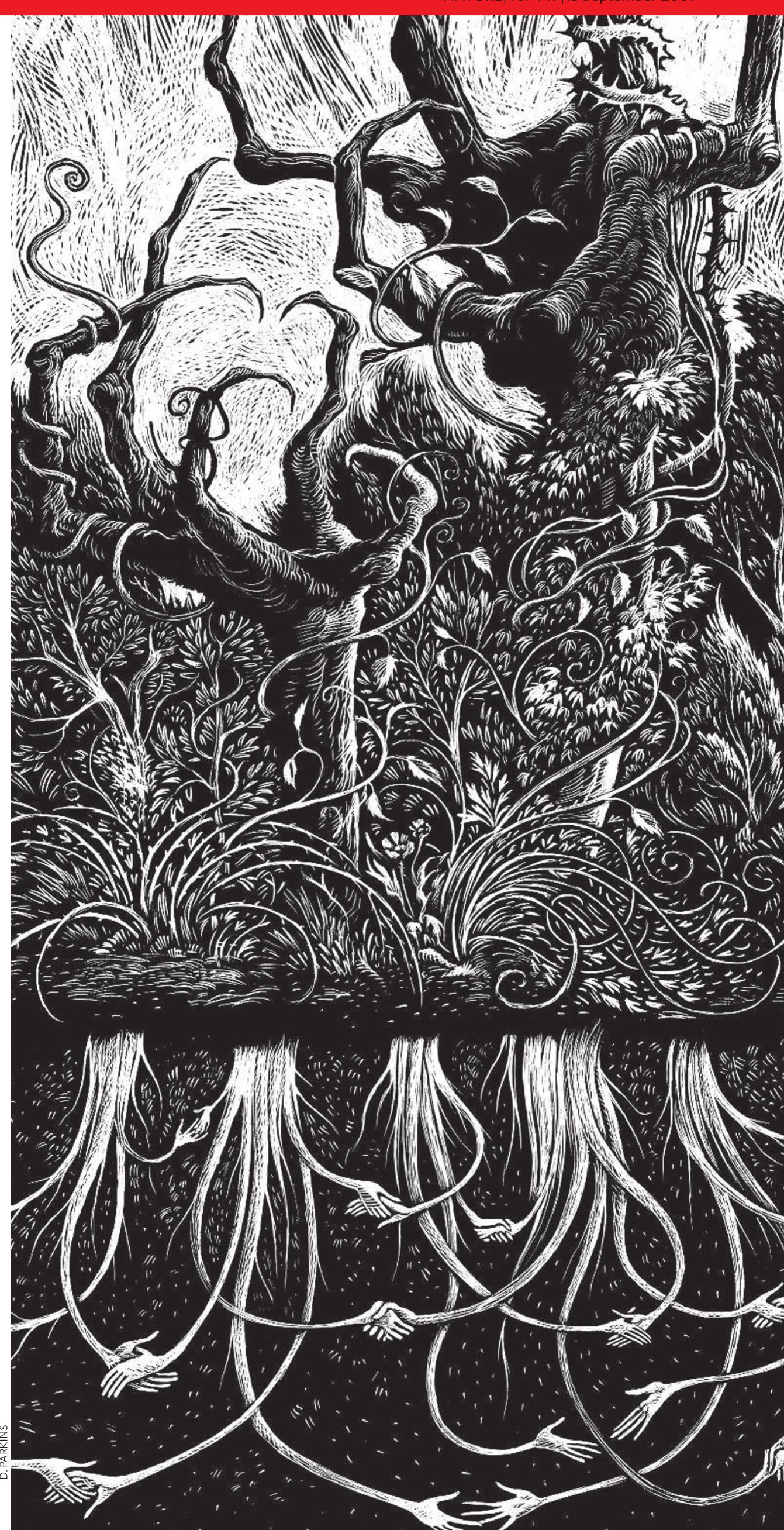


fungal fitness. Is it reflected in the number of mushrooms - spore-bearing, fruiting bodies - above ground, the size of the vast network below, or something else entirely? Even the process by which the plants and fungi exchange nutrients is unknown.

"We know so little that it's possible to propose some very naive hypotheses," says Martin Bidartondo of the Royal Botanical Gardens in Kew, London. Researchers are now looking to fill some of the huge gaps in their knowledge of the basic biology and natural history of fungal networks and to improve understanding of the their ecological consequences. Most can agree that fungal networks are real, and important to the lives of plants, but they disagree on how the effects manifest themselves.

\section{Give or take?}

About $80 \%$ of land plants have fungi called mycorrhizae growing in and on their roots. The fungi extend throughout the soil matrix; it has been estimated that a single gram of soil can contain 100 metres of mycorrhizal filaments. By vastly expanding root surface area, the fungi help plants extract water and nutrients, most importantly nitrogen and phosphorus, from the soil; they also protect plants against soil pathogens. In return, the plant provides carbohydrates. As much as $20-40 \%$ of the products of photosynthesis can flow back into the fungus. Most plants and fungi are promiscuous in their associations, mingling with a range of partner species, and creating the potential for one fungus to link the roots of dozens of different plants. DNA fingerprinting has shown such multiple links with matsutake fungus ${ }^{2}$.

But more than 400 species of plant have reneged on this contract. They do not photosynthesize at all and have no chlorophyll. Initially, scientists thought that they were decomposers; in fact they parasitize mycorrhizal fungi. This way of life has evolved many times in different plant groups, but it is particularly common in the orchid, heather and gentian families ${ }^{3}$. The more recent discovery that green plants such as Orthilia can also use fungal carbon suggests that the ability may be more widespread and ecologically significant than was once thought. "It was a dogma in botany that green plants were autotrophic, but this is no longer valid," says Gerhard Gebauer of the University of Bayreuth, Germany. A team including Gebauer and Bidartondo recently found five green orchid species that can use mycorrhizal carbon to thrive $e^{4}$ "This allows the orchids to move into the deepest shade in the forest," says Gebauer. "They can live as pioneers without any herbaceous competitors."
Bidartondo suspects that all orchids, which have very small, poorly provisioned seeds, take from fungi before they become self-sufficient. This start-up funding could have a huge ecological impact, he says: "If flow from fungi to plants happens when plants are getting established, it can really affect competition, even though the amounts moving might not be massive."

\section{Wood-wide web}

That some plants can take advantage of the fungal network is not in dispute - although it is not known how they do it. More contentious is whether the flow of nutrients between plants via fungi is a general and significant feature of

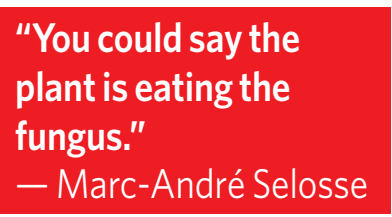

be seen even between different species. In a study ${ }^{6}$ published in Nature in 1997, Simard's team provided the leaves of paper birch (Betula papyrifera) and Douglas fir (Pseudotsuga menziesii) seedlings growing half a metre apart with carbon dioxide containing either carbon-14 or carbon-13 - rather than the usual carbon-12. They could thus detect the element moving in either direction between birch and fir. Move it did; what's more, trees growing in shade received more from the other plants in their network. After 9 days, an average of about $4 \%$ of the carbon isotopes given to each plant had shown up in the leaves of the other species, and the amount of carbon flowing from birch to pine doubled when the pine seedlings were shaded.

the 'wood-wide web' of forest ecosystems. Suzanne Simard of the University of British Columbia in Vancouver, Canada, says fungal networks may allow trees to support their own seedlings, perhaps providing the trees with an evolutionary benefit. "There's lots of evidence that mature trees facilitate the growth of conspecific seedlings beneath them, and the evidence is growing that networks are important," she says. Experiments with oaks, for example, show that acorns planted near their own kind do better than those planted near maples ${ }^{5}$, and Simard has found something similar with fir trees. Like Bidartondo, she thinks that these boosts to seedlings are mediated by fungi and are ecologically significant. "Early growth

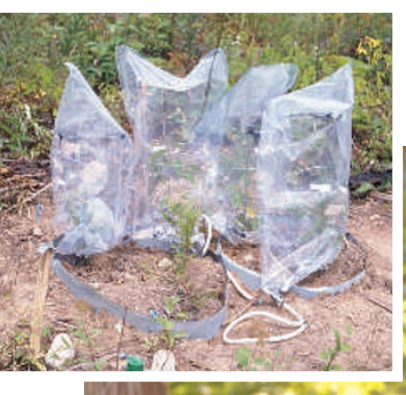
sets the trajectory of the ecosystem," she says.

Such effects can
Although laboratory studies had shown carbon moving between plants via fungi, Simard's study was a watershed in showing that the phenomenon happened in the field. The work demonstrated that carbon could flow both ways, that a significant amount of carbon moved, and that the quantity depended on environmental conditions. Since the work was published, other studies have shown that the timing of plant growth, as well as the light environment, affects the dynamics of transfer, with sugar maple seedlings gaining resources from a fast-growing perennial, the trout lily, in spring, and returning the favour in the autumn ${ }^{7}$. It has also been suggested that one thing that makes spotted knapweed a pernicious invasive weed in the United States is its ability to steal resources, via fungi, from other plants - one study found that as much as $15 \%$ of the carbon in the knapweed's shoot came

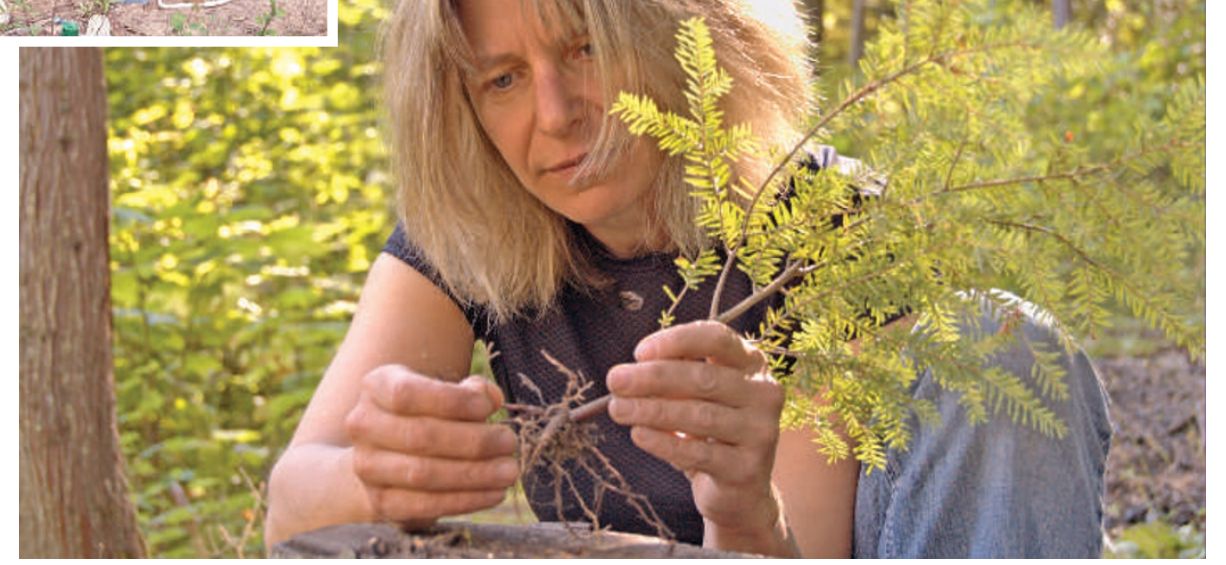

Fungal network: Suzanne Simard studies carbon transfer between young seedlings. 
from Idaho fescue, a native grass ${ }^{8}$.

Simard is currently working on the interactions between fungi and Douglas fir at the edge of the tree's range, in the dry regions where forest shades into grassland. In such places, water can also move between trees via fungi, she has found. "Mycorrhizae are more important in more stressful climates," she says. By helping plants cope with stress, and by helping seedlings survive, she thinks that fungal networks make plant communities more stable in the face of environmental stress, and quicker to recover from damage.

By distributing resources between different species, says Simard, fungi can preserve a variety of plant partners and insure against the effects of plant disease or herbivores. "If the fungus can form a bigger or more diverse network, its chances of survival are better," she says. Selosse says he thinks that fungi might help young plants to get established because it helps them compete with other fungi in the soil - nourishing an existing partnership might be a more effective strategy than seeking out new hosts. Alternatively, he suggests, it could be that some plants provide trace amounts of vitamins or even hormones in return for fungal carbon.

\section{Up-rooting claims}

But not everyone is convinced. "There's been some wishful thinking, and the evidence hasn't been looked at critically," says David Robinson of the University of Aberdeen, UK. "I don't think there's any convincing evidence for resource sharing between plants by mycorrhizal transfer." Robinson, working with Alistair Fitter of the University of York, has suggested that the carbon might have moved through the soil, rather than the fungi — in Simard's experiments, a small amount of radioactive carbon also showed up in a plant species that did not share mycorrhizae with the fir and birch. And experiments by Robinson, Fitter and other groups have found that, although elements do move between plants via fungi, they stay in the root system, and never make it into leaf and stem, suggesting that the resources are stored in the fungal tissue, and not released to the plant". "The moving carbon is primarily a fungal resource," says Robinson. Fitter adds that, from a darwinian viewpoint, it is "highly implausible" that a plant would benefit from helping its neighbours.

"There's no doubt that carbon moves through the soil," says Simard. "I think it goes through both mycorrhizae and soil." But she believes that evidence for transfer between plants has strengthened over the past decade - her group has recently redone the experiments with birch and fir, for example, and found a similar result. Experiments such as Robinson and

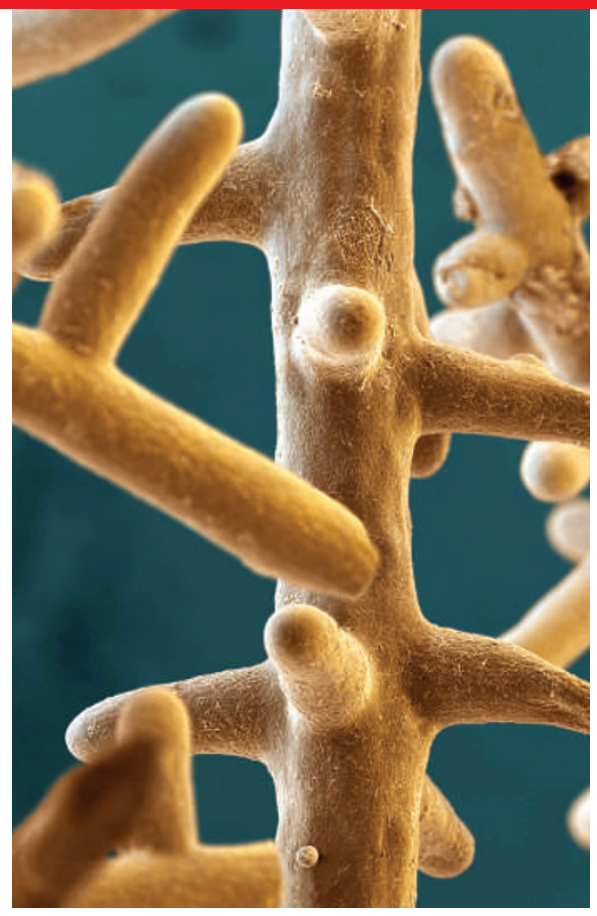

Fungi (thin threads) on the surface of plant roots form symbiotic associations with the plant.

Fitter's were conducted using grassland plants - a "quite different system" from woodlands, she says. Simard adds that, rather than simply shunting carbohydrates from one plant to another, the fungus might first use the carbon to make amino acids - nitrogen-containing compounds that form part of the usual carbohydrates-for-nitrogen exchange between plant and fungus. This avoids the problem of explaining why a fungus would want to give back its hard-won nourishment

Even if resources do not flow from plant to plant, the mycorrhizal network has other ways to influence plant interactions. "You don't need direct resource translocation to have benefit or disadvantage moving between plants via a fungal network," says Minna-Maarit Kytöviita of Oulu University in Finland. She has found that some seedlings do worse when hooked into the mycorrhizal network. In greenhouse experiments using herbaceous plants, seedlings do best with mycorrhizae. But when adult plants are present, seedlings do no better with mycorrhizae than without them. The fungi seem to be making the competition more intense - Kytöviita says they might be supplying more to the adult plant that gives more in return, and withhold favours from the seedling. She has also found that seedlings do better when their adult competitors are defoliated, and so less able to supply their fungi ${ }^{10}$.

It's in this spectrum of positive and negative interactions between plant and fungus that we should be seeking the influence of mycorrhizal networks, says John Klironomos of the University of Guelph, Canada. His experiments testing different combinations of plants and fungi have found that outcomes can range from exploitation, to mutualism, to neutrality ${ }^{11}$. A fungus might nourish one plant it links to, exploit another and be cheated by a third. It's the diversity of possible interactions between one fungus and the many plants in its network, not transfer between plants, that is ecologically significant, says Klironomos. "I'm convinced that mycorrhizal networks exist, but I'm not sure the mechanism of action is carbon transfer. What's more exciting is the other resources that the fungus is transferring to different plants, and the different amounts of carbon the fungus demands from plants. When you put all that into the equation you get some interesting dynamics."

\section{Filling in gaps}

What is clear is that researchers have their work cut out for some time to come. Studies so far have tended to look at two plant species linked by one fungus - a gross simplification of real-world diversity. Such studies have been snapshots, but fungi and trees can live for centuries. And biologists don't know how the links between plants and fungi affect the survival and reproduction of each party. For fungi, says Bidartondo, we're not even sure how to measure that.

Fitter believes that the priority should be to start filling in the large gaps in the understanding of mycorrhizal fungi. We don't know the extent of fungal diversity, he points out, or of the mechanisms of exchange between plants and fungi. "It seems almost certain that mycorrhizae have a huge importance in biodiversity and a number of ecosystem services. But we're a long way from knowing what that is," Fitter says. "Until we've eally got a proper understanding of basic fungal biology, we'll find it difficult to understand the ecological mechanisms."

John Whitfield is the author of In the Beat of a Heart: Life, Energy, and the Unity of Nature.

1. Tedersoo, L., Pellet, P., Köljalg, U. \& Selosse, M.-A. Oecologia 151, 206-217 (2007).

2. Lian, C., Narimatsu, M., Nara, K. \& Hogetsu, T. New Phytol. $171,825-836$ (2006)

3. Bidartondo, M. I. New Phytol. 167, 335-352 (2005).

4. Bidartondo, M. I. et al. Proc. R. Soc. Lond. B 271, 1799-1806 (2004)

5. Dickie, I. A., Koide, R. T. \& Steiner, K. C. Ecol. Monogr. 72, 505-521 (2002).

6. Simard, S. W. et al. Nature 388, 579-582 (1997)

7. Lerat, S. et al. Oecologia 132, 181-187 (2002).

8. Carey, E. V., Marler, M. J. \& Callaway, R. M. Plant Ecol. 172 133-141 (2004)

9. Pfeffer, P. E., Douds, D. D., Bucking, H., Schwartz, D. P. \& Shachar-Hill, Y. New Phytol. 163, 617-627 (2004)

10.Pietikäinen, A. \& Kytöviita, M.-M. J. Ecol. 95, 639-647 (2007).

11. Klironomos, J. N. Ecology 84, 2292-2301 (2003). 